COMO CITAR ESTE ARTÍCULO:

Ospina-Enciso, A.F. y Argüello-García, P.M. (2019). Editorial: Rutas y perspectivas para hacer y pensar alrededor del patrimonio cultural. Revista de Antropología y Sociología: VIRAJES, 21(2), 5-11. DOI: 10.17151/rasv.2019.21.2.1.

\title{
EDITORIAL
}

\section{Rutas y perspectivas para hacer y pensar alrededor del patrimonio cultural}

\author{
ANDRÉS FELIPE OSPINA-ENCISO * \\ PEDRO MARÍA ARGÜELLO-GARCÍA** \\ Maestría en Patrimonio Cultural, UPTC
}

El concepto de patrimonio cultural se ha transformado de forma radical en las últimas décadas. Del patrimonio delimitado institucionalmente, centrado en los monumentos que son funcionales para la teatralización de ideas y simbolismos alrededor de lo nacional, se viene transitando hacia la idea de patrimonio como una construcción social, ya no solo consagrada a los objetos sino recreada en los actores que interactúan con dichos elementos y los significados que les otorgan. Esta transformación deviene en una serie de cuestiones que con las nuevas definiciones del patrimonio cultural se tornan no solo fundamentales sino críticas en la actual agenda de este campo de estudios. Algunas de estas cuestiones están presentes en el conjunto de artículos que hoy presentamos a consideración de los lectores. A continuación, hacemos una breve presentación de los textos que componen este dossier, resaltando los aspectos en que cada uno de ellos aporta a las nuevas formas de comprensión e investigación respecto al patrimonio cultural.

El primer aspecto, que hoy día se observa como obviedad pero que en el pasado era desapercibido, tal vez sea mejor decir oculto, es la connotación profundamente política en los procesos de patrimonialización.

\footnotetext{
* Doctor en Antropología. Universidad Pedagógica y Tecnológica de Colombia. Tunja, Boyacá, Colombia. E-mail: andesosama@gmail.com. (1) ORCID: 0000-0003-3871-2700. Google Scholar

** Doctor en Antropología. Universidad Pedagógica y Tecnológica de Colombia. Tunja, Boyacá, Colombia. E-mail: pedro.arguello@uptc.edu.co.(- ORCID: 0000-0003-3570-2283. Google Scholar
} 
Ahora es claro que la decisión de conservar un conjunto de bienes considerados patrimoniales responde a una intención por exacerbar dos componentes sobre los que se construyó la idea de nación en Colombia: el catolicismo y el culto a los héroes de la independencia. El artículo “La virgen del Rosario de Chiquinquirá. Un referente simbólico patrimonial en la consolidación del Estado nación en Colombia" da cuenta del desarrollo histórico de este binomio y hace énfasis en la construcción de formas de patrimonio que legitimaran dicho proceso. El documento destaca cómo los esfuerzos conservacionistas del siglo XIX se dirigieron hacia la preservación y exaltación de la imaginería y el culto a referentes tan poderosos como el lienzo renovado de la Virgen de Chiquinquirá, una aparición mestiza que recoge los elementos característicos de la incipiente Colombia rural y urbana. Este no solo ha jugado un rol como elemento central de la devoción mariana en el país, sino que ha sido un acicate de la nacionalidad colombiana y el espíritu restaurador de la regeneración conservadora. Proceso similar ocurre con los monumentos y lugares alusivos a los padres fundadores de la patria (Lleras, 2014). En este documento, escrito por Nohora Alfonso, Jhon Alvarado y Nidian Alvarado, es posible comprender cómo la asociación con el catolicismo ha sido parte fundante de la nación colombiana y cómo la patrimonialización de bienes eclesiásticos responde justamente a una necesidad por conservar los bienes en quienes se supone se guarda lo más íntimo de nuestras raíces nacionales. La fiesta de coronación de esta virgen, que en 2019 cumplió 100 años, y su proceso de patrimonialización, denota la continuidad en el tiempo de la asociación iglesia-Estado, y allí los referentes patrimoniales mantienen dicha integración como un asunto naturalizado, instalado y hasta apropiado como referente de identidad compartida para feligreses, Estado y la institución religiosa.

La decisión respecto a qué conservar y qué no, trae consigo un segundo elemento de análisis: la esencialización del patrimonio. Se basa en la idea errónea de que un objeto patrimonial contrae solo un significado y, por ende, su esencia responde a un solo tipo de intencionalidad, temporalidad y racionalidad. El artículo de Nidia Manrique titulado "La historia y las memorias: el pasado presente en el Claustro de San Agustín de Tunja", muestra cómo una edificación valorada como patrimonio arquitectónico e histórico de una ciudad colonial ha tenido diferentes usos a lo largo de casi 500 años. Sin embargo, al momento de ser restaurada a finales del siglo XX para darle uso como centro cultural, solo se tuvo en cuenta su componente colonial asociado a su uso religioso, desconociendo las huellas de otros usos, tales como el penitenciario, del que este claustro también llamado panóptico, fue objeto desde mediados del siglo XIX hasta los años sesenta del siglo XX. En esta priorización del patrimonio religioso sobre el 
patrimonio penitenciario, las expresiones de los penitentes y acusados en el sitio de encierro fueron sistemáticamente borradas u ocultadas. La categoría de patrimonio incómodo emerge aquí como una antítesis de lo que se desea visibilizar y promover, y nos cuenta cómo hay cosas que socialmente se quieren olvidar, y en parte lo hacemos, borrando sus huellas. En este sentido, el patrimonio no solo es un campo de batalla donde se muestra lo que somos mediante el acto de visibilidad sino también a través del ocultamiento. Este texto propende analizar la "otra cara del patrimonio", a saber, aquella que debió ser destruida u ocultada a favor de la construcción de un objeto esencializado y atemporal.

El uso de un espacio para múltiples propósitos a través del tiempo da cuenta del carácter polisémico del patrimonio cultural. Cuando se mira detenidamente, casi todos los objetos patrimoniales son realmente palimpsestos que integran diferentes intencionalidades, no siempre compatibles unas con otras, por lo que un objeto o una manifestación patrimonial, en sí mismo, puede contener profundas contradicciones y contener diferentes voces, como también diversos significados, todos a su vez presentes. Como elementos de disímil utilización a través del tiempo, también aparecen dos situaciones discutidas en otros artículos que componen este dossier.

El texto de Jairo Moreno "Patrimonio industrial en Tunja. Memorias de crecimiento", hace alusión a una categoría poco estudiada en Colombia, conocida como patrimonio industrial. En la ciudad de Tunja, lugar de su indagación, es usual que cuando se piense en patrimonio inmueble se privilegie, como en muchas otras ciudades, el centro histórico, en razón a que alberga las edificaciones más antiguas y aquellas que guardan, como se expresó anteriormente, los constituyentes íntimos de la nación, la urbanización y la planificación territorial. Como consecuencia, las demás edificaciones, que no son consideradas históricas o seminales, son susceptibles de ser demolidas o arruinadas, pues no se les reconoce estatus patrimonial. El que sean seculares, más recientes, menos evocativas, más transitorias, hace de las edificaciones industriales de Tunja un conjunto de objetos sin valor patrimonial y, por ende, condenadas a su final destrucción en medio de la neblina de la expansión urbana. En este sentido, el artículo de Moreno exalta, mediante la evocación estética del corredor industrial del norte de Tunja, aquellas otras formas de patrimonio inmueble menos cercanas a los tradicionales moldes de valoración en los estudiosos del patrimonio, pero directamente relacionados con los referentes de identidad y transformación de una urbe intermedia que oscila entre la tradición y los procesos modernistas de expansión urbana. Más allá de un asunto de conservación, el estudio del patrimonio industrial trae consigo nuevas 
historias, nuevas formas de comprensión del espacio y nuevas articulaciones alrededor de lo que la gente participante o testigo de la arquitectura industrial de Tunja considera parte de su experiencia vital.

Otro caso que ejemplifica el carácter de palimpsesto de los objetos patrimoniales es presentado en el artículo "Del infierno al cielo en Boyacá: valoración patrimonial de un camino" de María Angélica Garzón y Lyda Moreno, a propósito del camino histórico que comunica a Turmequé con Ventaquemada, en Boyacá. A través del recorrido del camino es posible encontrar sus evidencias de vida, su composición y cómo se ha enclavado en el territorio durante años. El camino evoca diferentes épocas, culturas, formas sociales, intencionalidades y seguramente olvidos. Sus tramos, su materialidad, lo que de éste dicen y los elementos que se encuentran a su alrededor no son el patrimonio en sí, lo que constituye su patrimonio cultural es el conjunto de significados a él asignados por la gente que lo habita y lo transita. Análisis como éste desarticulan la ya obsoleta distinción entre patrimonio material y patrimonio inmaterial pues da cuenta de que, parafraseando a Maurice Godelier (1990), lo ideal requiere necesariamente un componente material, y viceversa.

Otra de las trasformaciones del patrimonio cultural es la discusión sobre quién construye, delimita y define lo que este patrimonio. Hoy día es claro que el patrimonio delimitado desde "arriba", entendiendo por "arriba" el Estado o sus agentes culturales, no necesariamente se "ancla" en las gentes y comunidades y por ende se hace insostenible a largo plazo. Claro ejemplo de ello es el caso mostrado por Jimena Lobo Guerrero, "Patrimonio sin dolientes: valor y uso del patrimonio. El caso del Museo Cultural de Arte Religioso de Mompox", donde la falta de un proyecto a largo plazo que implique el real envolvimiento de la gente en los procesos de patrimonialización deriva en una institución - el museo y su invaluable colección - sin dolientes, anacrónica y en riesgo de desaparecer. A esto se suma, la construcción de referentes patrimoniales de puertas para fuera, como es el caso de la puesta en valor y las inversiones públicas al patrimonio arquitectónico de Mompox, pensadas para la impresión de turistas y el impulso de actividades comerciales alrededor del complejo monumental valorado. Esto contrasta con los patrimonios creados de puertas para dentro, que no son los más reconocidos, ni los más protegidos, y sí enfrentan la indolencia de las instituciones que deben garantizar su protección. Para Lobo-Guerrero, esto ocurre por un principio de desigualdad estructural donde la mercantilización de los bienes culturales, y las condiciones de las realidades sociales de los actores no estimulan acciones de reconocimiento, valoración y protección de un patrimonio artístico y religioso que no es priorizado desde arriba y tampoco es apropiado de forma significativa por 
la población momposina. Lobo-Guerrero nos recuerda que el patrimonio no se hace por decreto, depende más de la articulación de acciones efectivas de puesta en valor entre los actores que aventuren por procesos de activación que superen la fijación por las fachadas de lugares históricos y se internen en los significados y potenciales de los patrimonios desde adentro.

En los ejercicios de investigación y formación, desde su creación hace cinco años, la Maestría en Patrimonio Cultural de la UPTC ha apostado por pensar el patrimonio cultural de una forma diferente a la tradicional visión del patrimonio centrada en los monumentos. Asumimos que para comprender los procesos de patrimonialización debíamos enfocarnos en la gente y por tal razón hemos hecho uso de metodologías de investigación que giran en torno a lo etnográfico, a la relación de conocimiento y sentido que se produce entre poblaciones e investigadores. Cuando se hace etnografía se corre el feliz riesgo de encontrarse con aspectos inesperados que muestran nuevos caminos, pero sobre todo permiten entender cuán complejos pueden llegar a ser los campos y los asuntos del patrimonio cultural. En su mayoría, los artículos de este dossier usan las técnicas y sensibilidad etnográficas, lo cual ha permitido enriquecer la mirada patrimonial y explorar formas de escritura, descripción, inventario y significación no tan tradicionales.

El artículo de Karen Ochoa, "La envidia artesanal, un mecanismo de protección y salvaguardia", es especialmente ilustrativo respecto a la capacidad del trabajo etnográfico para comprender elementos subyacentes a algunas prácticas que queremos entender como patrimoniales. En su interés por rescatar las prácticas asociadas al bordado, Karen encuentra que la envidia y los celos son parte estructurante de los sentimientos asociados a ellas. La existencia de sentimientos como la envidia y los celos, y por ende los silencios que de ellas derivan, suponen serias implicaciones respecto a la valoración, conservación y promoción de oficios tradicionales y que por ende se quieren patrimonializar. En los manuales de patrimonio cultural se asume tácitamente que la gente quiere conservar sus saberes y que entiende que para hacerlo requiere transmitirlo. No obstante, la autora encuentra que no es así y que, procurar salvaguardar un oficio como el bordado, requeriría una mediación que tenga como punto de partida las consideraciones respecto al deseo de las artesanas del bordado de guardar el conocimiento para sí, lo cual de plano va en contravía de lo que se supone es el fundamento del patrimonio mismo. En fin, casos como este muestran que lo patrimonial no es un asunto de escuetos inventarios de técnicas, sino que para estudiarlo se debe acudir por lo menos a descripciones densas, en el sentido ya clásico esbozado por Geertz.

Otro caso en que la experiencia etnográfica se abre camino es con la propuesta de Olga Judit García, “Cocinas tradicionales en declive: 
riesgo para el patrimonio cultural y la seguridad alimentaria en Guayatá". La autora propone que las calidades de la seguridad alimentaria de una población están directamente relacionadas con las puestas en valor de su patrimonio gastronómico. García encuentra que, en poblaciones rurales como en la vereda Chitavita donde elaboró su trabajo, hay un deterioro en las condiciones del patrimonio gastronómico y en general de la alimentación de sus pobladores. De allí que haga énfasis en el reconocimiento de las formas de producción de los alimentos, los sistemas de intercambio, las festividades, los hábitos, las tradiciones y las reglas de comensalidad como estrategias multiusos que hagan de la identidad y la apropiación de lo que se come oportunidades para mantener y fortalecer el sistema alimentario, promoviendo vínculos e interacciones en las sociedades de tipo rural. Esto lo hace identificando, mediante una pesquisa etnográfica, cuáles son los elementos del patrimonio gastronómico, sus características, sus riesgos y valoraciones.

En un ejercicio de análisis y divulgación de los procesos de identificación del patrimonio artístico, e identificando otras formas de preservación e investigación que usen las nuevas tecnologías para la sistematización y análisis de información, destaca el trabajo de Jhon Garcés, "Arte, patrimonio y la pérdida de conocimiento de la pintura de caballete en Colombia. Construcción de un sistema integrado de información", sobre el Sistema de Información Científica de Arte y Patrimonio -SICAP-. Esta propuesta plantea alternativas para la recolección, sistematización y análisis de información técnica e iconográfica de un conjunto de datos sobre pinturas de caballete en Colombia que van del siglo XVI al XIX, cruzando diferentes elementos que permitan conocer estilos, formas de creación, técnicas de trabajo y tendencias en el desarrollo de este tipo arte. Dicha herramienta nos propone, desde un ejercicio de metodología y análisis basado en la teoría fundamentada, una alternativa de trabajo que aporte a las pesquisas con datos y contenidos organizados digitalmente para su interpretación, salvaguarda y divulgación.

Todos los trabajos que componen este volumen son llamados a la apertura de vías metodológicas y a la apuesta por nuevos alcances comprensivos sobre el patrimonio cultural en relación con los actores y las circunstancias que los significan. El conjunto de manuscritos nos enseña que los elementos de legado y tradición, clásicos de la valoración patrimonial, son apuestas más contemporáneas que pasadas, que tienen un vínculo estrecho con las dinámicas, contextos, oportunidades y conflictos que experimentan las sociedades en el presente. En consecuencia, el patrimonio cultural es un campo dinámico que exige mirar con detalle sus nuevas creaciones y 
pasar revista de aquellas propuestas inquietantes, creativas, vinculantes de otros campos de conocimiento, que contribuyan a una valoración asertiva de lo que las sociedades activan como patrimonios, significados colectivos y referentes de identidad.

\section{Referencias bibliográficas}

Godelier, M. (1990). Lo ideal y lo material. Madrid: Taurus.

Lleras, R. (2014). La producción del patrimonio cultural restaurado. Boletín de Historia y Antigüedades, 101(859), 381-395. 